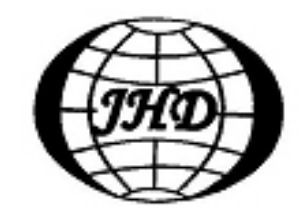

www.sciencedirect.com/ science/journal/10016058

\title{
FLOW-PIPE-SEEPAGE COUPLING ANALYSIS OF SPANNING INITIATION OF A PARTIALLY-EMBEDDED PIPELINE*
}

\section{GAO Fu-ping}

Key Laboratory for Hydrodynamics and Ocean Engineering, Institute of Mechanics, Chinese Academy of Sciences, Beijing 100190, China, E-mail: fpgao@imech.ac.cn

LUO Cheng-cai

Centre for Offshore Foundation Systems, The University of Western Australia, Nedlands, WA 6907, Australia

(Received November 15, 2009, Revised January 15, 2010)

\begin{abstract}
The initiation of pipeline spanning involves the coupling between the flow over the pipeline and the seepage-flow in the soil underneath the pipeline. The pipeline spanning initiation is experimentally observed and discussed in this article. It is qualitatively indicated that the pressure-drop induced soil seepage failure is the predominant cause for pipeline spanning initiation. A flow-pipe-seepage sequential coupling Finite Element Method (FEM) model is proposed to simulate the coupling between the water flow-field and the soil seepage-field. A critical hydraulic gradient is obtained for oblique seepage failure of the sand in the direction tangent to the pipe. Parametric study is performed to investigate the effects of inflow velocity, pipe embedment on the pressure-drop, and the effects of soil internal friction angle and pipe embedment-to-diameter ratio on the critical flow velocity for pipeline spanning initiation. It is indicated that the dimensionless critical flow velocity changes approximately linearly with the soil internal friction angle for the submarine pipeline partially-embedded in a sandy seabed.
\end{abstract}

Key words: submarine pipeline, pipeline spanning, seepage failure, flow-pipe-seepage coupling

\section{Introduction}

For a submarine pipeline directly laid upon seafloor, there usually exists a certain embedment into the soil. Under the action of ocean environmental loads, the soil particles underneath the partially embedded pipeline may be removed to finally lead to the occurrence of pipeline spanning ${ }^{[1]}$. The pipeline spanning involves a coupling process, i.e., the coupling between the flow above the pipe and the seepage flow below the pipe, as illustrated in Fig.1.

* Project supported by the National Natural Science Foundation of China (Grant No. 10532070), the Knowledge Innovation Project of Chinese Academy of Sciences (Grant No. KJCX2-YW-L02).

Biography: GAO Fu-ping (1973- ), Male, Ph. D., Professor

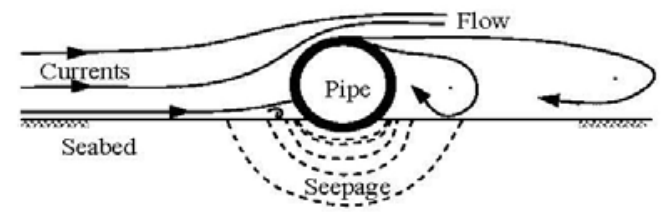

Fig.1 Illustration of the coupling between the flow over a pipeline and the seepage-flow in the soil underneath the pipeline

The pipeline spans may experience Vortex-Induced Vibrations (VIV), which are widely recognized as one of the main causes for fatigue damage of pipelines ${ }^{[2,3]}$. Therefore, to further reveal the mechanism of the initiation of pipeline spanning underneath a partially 
embedded pipeline would be important for the stability design of submarine pipeline systems ${ }^{[4]}$.

In the past few decades, the mechanism of the initiation of pipeline spanning underneath pipelines in ocean environments has attracted numerous studies ${ }^{[5]}$. The onset of pipeline spanning around the pipeline in steady currents was mainly investigated experimentally, such as the studies by $\mathrm{Mao}^{[6]}$, $\mathrm{Chiew}^{[7]}$, and Sumer et al. $^{[8]}$. Mao ${ }^{[6]}$ gave a description of the vortices formed in front and at the rear of the pipe and discussed the pressure coefficient distribution along the sand bed near the pipe measured by Bearman and Zdrvkovich $^{[9]}$. It was deduced that the pressure drop between the upstream and downstream of the partially embedded pipe may cause the seepage flow within the underlying soils ${ }^{[6]}$. Chiew $^{[7]}$ verified the mechanism of pipeline spanning due to seepage flow by a series of comparative experiments. In the tests with impermeable plate being placed upstream of the pipe by Chiew ${ }^{[7]}$, no pipeline spanning was observed as the impermeable plate would effectively reduce the pressure gradient and thus avoid soil piping. Sumer et al. $^{[8]}$ further conducted a series of small-scale flume tests to study the onset of scour below pipelines and the self-burial in both waves and currents, and obtained some empirical relationships between the non-dimensional flow velocity and the initial pipe embedment.

Besides the aforementioned experimental simulations, numerical methods were also adopted for simulations, most of which were concentrated on the flow over the near-wall cylinder (pipe) or the sediment transport surrounding the pipe for predicting equilibrium scour-hole profiles around the pipe without initial embedment into the soil, i.e., with the pipe being laid above the seabed with some gap between the pipe and the seabed ${ }^{[10-12]}$. Lu et al. ${ }^{[13]}$ numerically investigated local scour around submarine pipelines using a renormalized group turbulence model. The flow structure around the pipe, the shear stress distribution on the seabed and the equilibrium profiles of the scour hole were obtained and compared with experimental results. However, the seepage flow in the soil underneath the pipe was not well taken into account in those numerical studies. So far, the numerical investigations on the onset of pipeline spanning of pipelines are few and far between. Liang and Cheng ${ }^{[14]}$ and Yang et al. ${ }^{[15]}$ simulated numerically the flow over a pipeline and the seepage flow underneath the pipeline in currents. Zang et al. ${ }^{\text {[16] }}$ recently also proposed an uncoupled numerical model for onset of scour below a submarine pipeline, in which the critical hydraulic gradient was still simply set as the average value along the pipe-soil interface, and the effects of the internal friction angle of the sand and the pipe embedment were not taken into account. Moreover, in these numerical models, the flow-field and the seepage-flow were uncoupled: the flow-field around the pipe was calculated to obtain the pressure distribution along the rigid bed, with the obtained pressure distribution as the boundary conditions, the seepage flow in the underlying soils was then calculated. That is, the flow-field and seepage-field were not obtained simultaneously, which would be inconvenient for parametric studies. To establish a flow-pipe-seepage coupling numerical model including a more reasonable critical hydraulic gradient for seepage failure below a partiallyembedded offshore pipeline is highly desirable for further studies of the mechanism of pipeline spanning initiation.

In this study, observations were experimentally made of the partially-embedded pipeline being suspended (pipeline spanning initiation) and were followed with a discussion. To further reveal the mechanism of pipeline spanning, a flow-pipe-seepage sequential coupling Finite Element Method (FEM) model is proposed for implementing the coupling between the water flow-field and the soil seepage-field around the pipeline partially embedded in a sandy seabed. Parametric study is then performed to investigate the influential factors of the pressure drop and the critical velocity on pipeline spanning initiation.

\section{Observations of pipeline spanning initiation}

To simulate the process of the partially embedded pipe being suspended in currents, a series of experiments were conducted in a flume $(0.5 \mathrm{~m}$ wide, $0.6 \mathrm{~m}$ deep and $19 \mathrm{~m}$ long), which can generate steady flows with velocities up to approximately $0.6 \mathrm{~m} / \mathrm{s}^{[15]}$.

As shown in Fig.2, the model pipe made of stainless steel was attached to the supporting beam with two screw poles, with which the vertical position of the model pipe can be adjusted to the desired initial embedment into the soil. Raining sand technique was employed for preparing a homogeneous sand bed. In the tests, a type of fine silica sand was adopted for simulating a sandy seabed, whose physical characteristics are as follows: the mean particle diameter of sands $d_{50}=1.2 \times 10^{-4} \mathrm{~m}$, the uniformity coefficient of sands $C_{u}=1.41$, the mass density of soil grains $\rho_{s}=2.66 \times 10^{3} \mathrm{~kg} / \mathrm{m}^{3}$, the void ratio of sands $e=0.86 \quad$ (i.e., the porosity of sands $n=e /(1+e)=0.46)$, the buoyant unit weight of sands $\gamma^{\prime}=8.7 \mathrm{kN} / \mathrm{m}^{3}$, the relative density of sands $D_{r}=0.6$, the internal friction angle of sands $\phi=42^{\circ}$. In the experiments, the flow speed was increased gradually. Meanwhile, the whole process of sediment transportion around the embedded pipe under the 
action of a steady flow was recorded with a digital video camera through the transparent glass sidewalls of the flume.
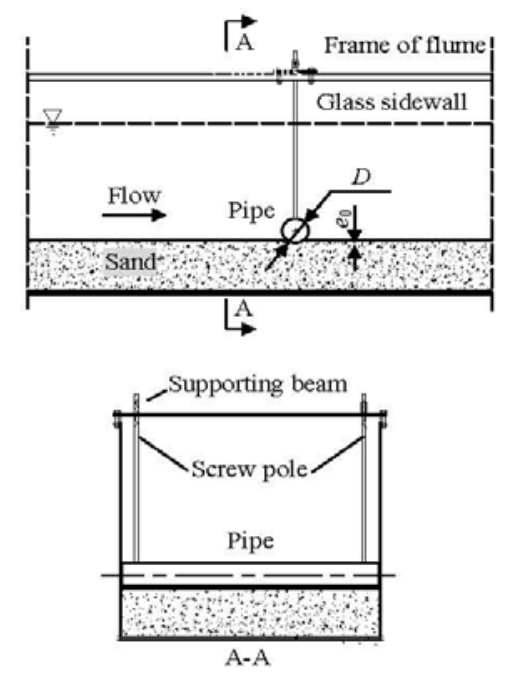

Fig.2 Experimental setup for initiation of pipeline spanning

In the process of the partially-embedded pipeline being suspended under the action of currents, there are usually three characteristic phases (see Fig.3):

(1) Phase I: local scour

It is observed in experiments that the vortices formed around the test pipe tend to increase the shear stress on the surface of the sandy bed. When the critical Shields number for the onset of scour is reached, a local scour would be induced at both upstream and downstream sides of the pipe (see Fig.3(a)).

(2) Phase II: onset of pipeline spanning

The pressure drop due to the presence of the pipe structure would further induce the seepage flow within the sands beneath the pipe. When the flow velocity becomes high enough (e.g., $U=0.17 \mathrm{~m} / \mathrm{s}$ in the present tests), the seepage failure can be observed to take place sporadically just underneath the partially embedded pipe at its downstream side, as shown in Fig.3(b). With increasing pressure gradients below the pipe, a point is reached when the surface of the sand at the immediate downstream of the pipe begins to rise, as is consistent with the piping process described in conjunction with dams in Terzaghi (1948).

(3) Phase III: Complete suspension of pipe

After the seepage failure at several sporadic spots along the pipe, the perforation zones would spread rapidly and finally result in the complete suspension of the pipe (see Fig.3(c)).

Experimental observations show that, in the process of pipeline being suspended, the onset of pipeline spanning underneath the pipe is not inevitably caused by the local scour around the pipe, because the positions for the onset of soil erosion are just beneath the pipe at the downstream side (see Fig.3(b)), which are different from the locations for the local scour around the pipe (see Fig.3(a)). The lee-wake induced local scour always occurs in the process of the pipe being suspended, but its effect on pipeline spanning initiation is ignorable. The pressure drop induced seepage failure underneath the pipe is the main cause for the onset of tunnel erosion, which would eventually make the pipe completely suspended.

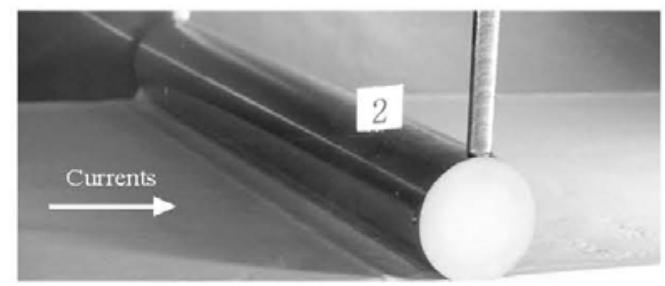

(a) Local scour

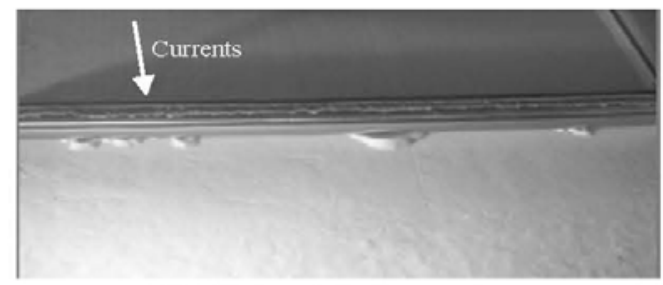

(b) Initiation of pipeline spanning

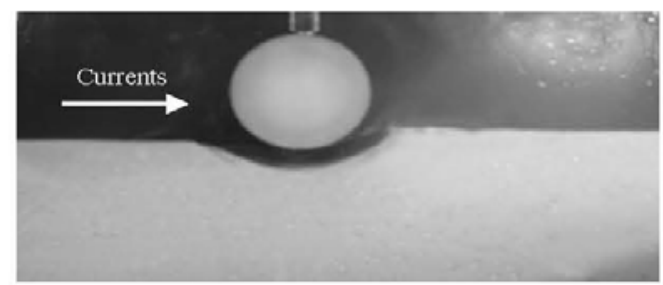

(c) Complete suspension of the pipe

Fig.3 The process of a partially embedded pipe being suspended in currents

\section{Flow-pipe-seepage coupling FEM model}

3.1 Governing equations for flow over a pipe and seepage underneath the pipe

As aforementioned, the process of scour underneath a pipeline in currents involves the coupling of two flow-fields, i.e., the flow-field around the pipeline and the seepage-field within the underlying soil. In this study, the FEM is employed to simulate this steady-state process.

The governing equations for the incompressible flow above seabed are the two-dimensional Reynolds-Averaged Navier-Stokes (RANS) equation and the continuity equation, which can be written in 
the Cartesian coordinate system as

$$
\frac{\partial u_{i}}{\partial t}+u_{j} \frac{\partial u_{i}}{\partial x_{j}}=-\frac{1}{\rho} \frac{\partial p}{\partial x_{i}}+v \frac{\partial^{2} u_{i}}{\partial x_{j} \partial x_{j}}-\frac{\partial}{\partial x_{j}}\left(\overline{u_{i}^{\prime} u_{j}^{\prime}}\right)
$$

$$
\frac{\partial u_{i}}{\partial x_{i}}=0
$$

where $u_{i}$ is the mean velocity of fluid, $u_{i}^{\prime}$ and $u_{j}^{\prime}$ are the fluctuating velocities, $t$ is the time, $\rho$ is the density of fluid, $p$ is the pressure of fluid, $v$ is the kinematic viscosity of fluid, $x_{i}$ (or $x_{j}$ ) is the coordinates in horizontal and vertical directions, respectively. For the steady flow, the term $\partial u_{i} / \partial t$ in Eq.(1) vanishes. The term of turbulent fluxes can be approximated by Boussinesq assumption as

$$
-\overline{u_{i}^{\prime} u_{j}^{\prime}}=v_{t}\left(\frac{\partial u_{i}}{\partial x_{j}}+\frac{\partial u_{j}}{\partial x_{i}}\right)-\frac{2}{3} k \delta_{i j}
$$

in which $k$ is the turbulent kinetic energy, i.e., $k=\overline{u_{i}^{\prime} u_{i}^{\prime}} / 2, v_{t}$ is turbulent viscosity. A turbulence model is necessary to provide a value for the turbulent viscosity $\left(v_{t}\right)$ throughout the flow field. The standard $k-\varepsilon$ model is employed, i.e.,

$$
\begin{gathered}
\frac{\partial k}{\partial t}+\frac{\partial}{\partial x_{i}}\left(u_{i} k\right)=\frac{\partial}{\partial x_{j}}\left[\left(v+\frac{v_{t}}{\sigma_{k}}\right) \frac{\partial k}{\partial x_{j}}\right]+G_{k}-\varepsilon \\
\frac{\partial \varepsilon}{\partial t}+\frac{\partial}{\partial x_{i}}\left(u_{i} \varepsilon\right)=\frac{\partial}{\partial x_{j}}\left[\left(v+\frac{v_{t}}{\sigma_{\varepsilon}}\right) \frac{\partial \varepsilon}{\partial x_{j}}\right]+ \\
C_{1 \varepsilon} \frac{\varepsilon}{k} G_{k}-C_{2 \varepsilon} \frac{\varepsilon^{2}}{k}
\end{gathered}
$$

where the turbulent viscosity $v_{t}$ is defined as $v_{t}=C_{\mu} k^{2} / \varepsilon$, with $\varepsilon$ denoting the turbulent energy dissipation rate, $G_{k}$ is defined as $G_{k}=-\overline{u_{i}^{\prime} u_{j}^{\prime}} \partial u_{i} / \partial x_{j}$, the constants are: $C_{1 \varepsilon}=1.44, \quad C_{2 \varepsilon}=1.92$, $C_{\mu}=0.09, \sigma_{k}=1.0, \sigma_{\varepsilon}=1.3$.

For the two-dimensional steady seepage-flow through an incompressible medium obeying Darcy's law, its continuity equation in the $x y$ plane becomes $k_{x} \frac{\partial^{2} h}{\partial x^{2}}+k_{y} \frac{\partial^{2} h}{\partial y^{2}}=0$

in which $k_{x}$ and $k_{y}$ are the coefficients of permeability in directions $x, y$, respectively, $h(=p / \rho g)$ is the hydraulic head, $p$ is the seepage pressure $^{[17]}$. In this study, the seabed soil is assumed to be isotropic with respect to permeability, i.e., $k_{x}=k_{y}=k$, then the continuity Eq.(6) is simplified to Laplace's equation:

$\frac{\partial^{2} h}{\partial x^{2}}+\frac{\partial^{2} h}{\partial y^{2}}=0$

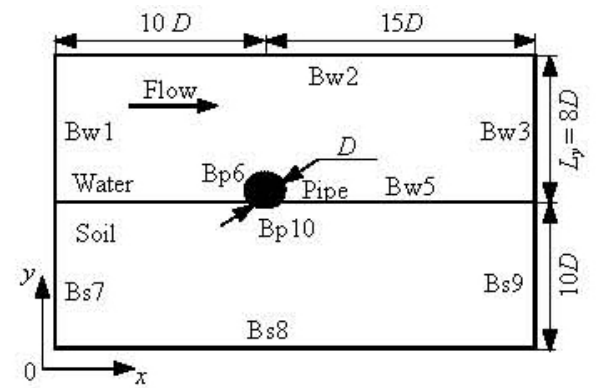

Fig.4 Illustration of computational zone and hydraulic boundary conditions (not in scale)

\subsection{Hydraulic boundary conditions}

In order to solve the above governing equations for the flow above the pipeline and the seepage flow within the underlying seabed in a whole process, the sequential coupling method is implemented by imposing the RANS-continuity derived pressure distribution along the bed surface (Bw4 and Bw5 in Fig.4) as a Dirichlet boundary for the seepage-flow calculation. Compared with the flow velocities around the pipe, the seepage flow velocities in the porous bed are generally small in magnitude. Therefore, it is reasonable to adopt the no-slip/no-flow conditions at the sediment-water interface. The hydraulic boundary conditions are treated as follows: (1) at the left-hand side inflow boundary (Bw1 in Fig.4), a constant undisturbed flow velocity is specified, i.e., $u_{1}=U$, (2) the top of the flow (Bw2) is treated as a no-flow symmetry boundary, (3) at the outflow boundary (Bw3), the pressure takes a reference value $p=0$, whereas the other flow variables are allowed to adjust freely with zero $x$-gradient conditions, (4) on the surface of the seabed $(\mathrm{Bw} 4,5)$ and the pipeline (Bp6), the logarithmic wall function is implemented, in the 
seepage domain, the pressure heads along the surface of sand $(\mathrm{Bw} 4,5)$ are expressed by the pressure of the flow field, (5) the pipeline surface contacting with the sediment (Bp10) and the other boundaries of the porous sand domain (Bs7, 8, 9) are treated as Neumann boundary condition, i.e., $n \bullet \nabla h=0$.

\subsection{FEM computational method}

The stability and the accuracy of the RANS solution are ensured by using Lagrange p2-p1 elements $^{[18]}$. In the computational domain, triangular elements are adopted and denser computational grids are used in proximity to the pipe for computation efficiency (see Fig.5). The grid spacing sensitivity is tested. In the adopted model, the number of the triangular elements ranges approximately from $1.8 \times 10^{4}$ to $2.2 \times 10^{4}$, and the highest resolution is about $0.005 \mathrm{~m}-0.01 \mathrm{~m}$ depending on the corresponding computational domain size. The chosen density of elements ensures that the computational results are stable and the process of computation is efficient.

Unlike previous studies, which first solve the RANS equation and then the Laplace's equation using the obtained pressure on the surface of the seabed, this model deals with the coupling of these two fields by ensuing the continuity of water-soil interface pressure in every computational step. The coupling in every computational step is more reasonably treated in view of reflecting the real physical process.

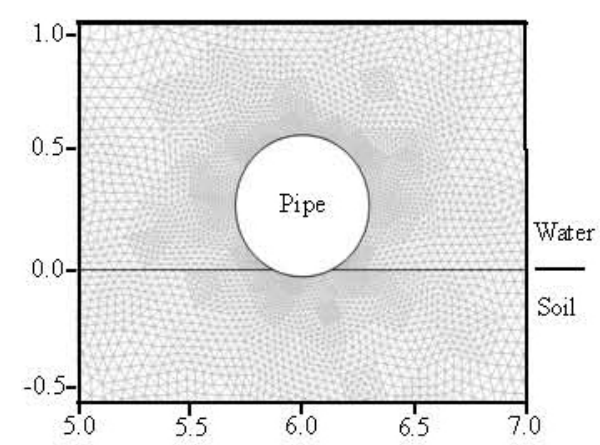

Fig.5 Computational mesh in the proximity of the pipe

\subsection{Derivation of criterion for soil seepage failure underneath the pipe}

The experimental observations show that the pipeline spanning is always initiated at the immediate downstream of the pipe, and the sand-slice breaks out in the tangential direction to the partially embedded smooth pipe (see slice-E in Fig.6). Therefore, for the criterion of seepage failure underneath the partially embedded pipe, the slope angle $(\beta)$ for the seepage-flow inducing pipeline spanning should be taken into account. To derive the critical hydraulic gradient $\left(i_{c}\right)$ for the soil seepage failure, the equilibrium analysis is performed on the slice- $E$ of the sand element at the seepage-flow exit (see Fig.6).

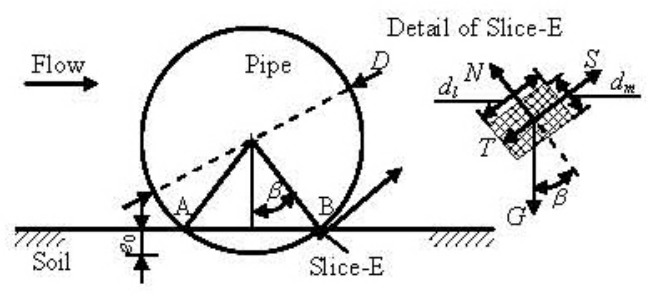

Fig.6 Equilibrium of forces on the sand slice at the immediate downstream of the pipe

As shown in Fig.6, the forces acting on the slice-E $\left(d_{l} d_{m}\right)$ mainly include the submerged gravitational force ( $G$ ), the supporting force $(N)$, the sliding frictional force $(T)$, and the seepage force $(S)$ :

$G=(1-n)\left(\rho_{s}-\rho_{w}\right) g d_{l} d_{m}$

$N=G \cos \beta$

$T=N \tan \phi$

$S=i_{\text {exit }} \rho_{w} g d_{l} d_{m}$

where $\beta$ is the half of the contacting angle $(1 / 2 \angle \mathrm{AOB})$, or the slope angle of the seepage-flow at the exit position, $\rho_{s}$ is the mass density of sand grains, $\rho_{w}$ is the mass density of water, $g$ is the gravitational acceleration, $\phi$ is the internal friction angle of sands, $i_{\text {exit }}$ is the hydraulic gradient at the seepage-flow exit (see, slice-E in Fig.6) . The relationship between the angle $\beta$ and the initial embedment-to-diameter ratio $\left(e_{0} / D\right)$ is

$\beta=\arccos \left(1-\frac{2 e_{0}}{D}\right)$ for $\frac{e_{0}}{D} \leq 0.5$

in which $e_{0}$ is the initial pipe embedment, $D$ is the diameter of the pipe. The sand slice may break under the following condition:

$S \geq G \sin \beta+T$

Substituting Eqs.(8)-(11) into Eq.(13), the critical hydraulic gradient $\left(i_{c}\right)$ for the seepage failure 
underneath the smooth pipe can be obtained as

$$
\begin{gathered}
i_{\text {exit }} \geq i_{c}=\underbrace{(\sin \beta+\cos \beta \tan \phi)}_{N_{r}} \\
\underbrace{(1-n)\left(\frac{\rho_{s}-\rho_{w}}{\rho_{w}}\right)}_{i_{c o}}
\end{gathered}
$$

That is,

$$
i_{c}=N_{r} i_{c 0}
$$

where

$N_{r}=(\sin \beta+\cos \beta \tan \phi)$,

$i_{c 0}=(1-n)\left(\frac{\rho_{s}-\rho_{w}}{\rho_{w}}\right)$,

which is the commonly-used critical hydraulic gradient for piping due to upward vertical seepage in the soil mass around hydraulic structures, such as a single-row pile ${ }^{[17]}$. The calculated hydraulic gradient at the seepage-flow exit is chosen as the mean value over the slice-E with $d_{l}=d_{m}=30 d_{50}$. In this critical hydraulic gradient formula (14), the two additional parameters are included, i.e., the internal friction angle of soil $(\phi)$ and the slope angle of the seepage-flow at the exit position ( $\beta$ ). The relations between $N_{r}$ and $\beta$ for the various values of $\phi$ (e.g., $\phi=30^{\circ}, 45^{\circ}$ and $50^{\circ}$ ) are shown in Fig.7. When $\beta=90^{\circ}$ (the pipe is half buried), the coefficient $N_{r}$ is equal to 1.0 (i.e. $i_{c}=i_{c 0}$ ), indicating that the effects of the soil internal friction angle do not exist any longer.

\subsection{Validation of the numerical model}

\subsubsection{Examination of blockage effects}

In the offshore fields, submarine pipelines are generally laid underwater with water depths much larger than their diameters. In the numerical simulation, the height of water domain (see Fig.4) may bring about blockage effects on the local pressure distributions in the proximity of the pipeline. So, it is worthwhile to examine the influence of the height of water domain on the pressure distribution along the water-soil interface around the pipeline.

In the numerical model, a prototype size pipe (e.g., $D=0.6 \mathrm{~m}$ ) is located in a position $x=0.6 \mathrm{~m}$ with a given embedment. The upstream and the downstream boundaries are $10 D$ and $15 D$ from the center of the pipe, respectively. The soil depth is chosen as $10 D$. In the parametric study for examination of the blockage effects, the height of water domain $\left(L_{y}\right)$ is set as $L_{y}=3 D, 4 D, 6 D$, and $8 D$, respectively, and other parameters are kept constant, i.e., $U=1.0 \mathrm{~m} / \mathrm{s}, D=0.6 \mathrm{~m}$, $e_{0} / D=0.05$.

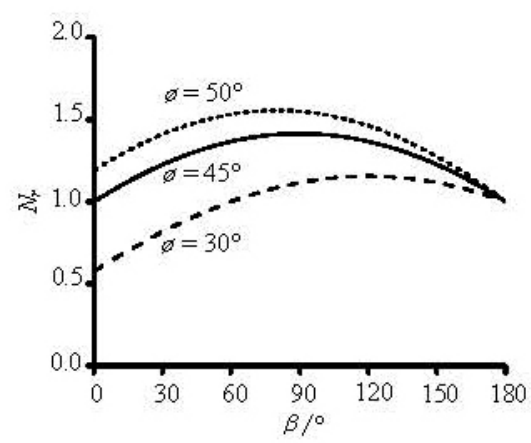

Fig.7 $N_{r}$ versus $\beta$ for various values of internal friction angle of soil

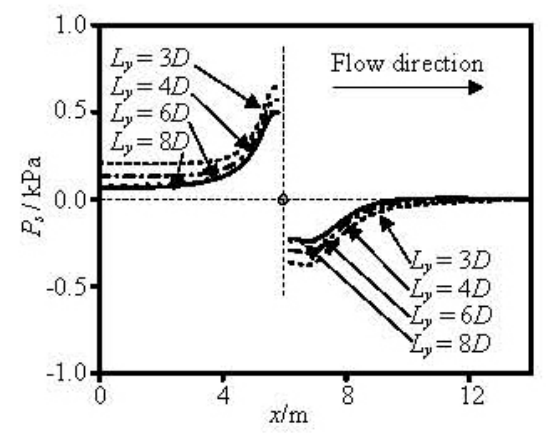

Fig.8 Pressure distributions at the water-soil interface near the pipe for various water domain heights $(D=0.6 \mathrm{~m}$, $e_{0} / D=0.05, U=1.0 \mathrm{~m} / \mathrm{s}$, the pipe is located at position $x=0.6 \mathrm{~m}$ )

The pressure distributions at the water-soil interface near the pipe for various values of $L_{y}$ are shown in Fig.8. It is indicated that, the pressure at the water-soil interface $\left(P_{s}\right)$ is greatly affected by $L_{y}$ in the examined range, i.e., $3 D<L_{y}<8 D$. The magnitudes of $P_{s}$ are much larger for small values of $L_{y}$, (e.g., $L_{y}=2 D$ ). With the increase of $L_{y}$, its effects on the local pressure distribution (i.e., the blockage effects) are diminishing. The difference in the local pressure distribution is ignorable between the case of $L_{y}=6 D$ and that of $L_{y}=8 D$. That is, the blockage effects could be ignored under large 
water-depth conditions (e.g., $L_{y}>6 D$, see Fig.8). In the following sections, if not specially stated, the height of water domain is chosen as $L_{y}=8 D$, so as to avoid the blockage effects.

3.5.2 Flow-field and seepage-field around the partially embedded pipe

With the proposed numerical model, the flowfield over and around the pipe and the seepage-field underneath the partially-embedded pipe can be obtained simultaneously. Figure 9 illustrates the distributions of the flow pressure and the seepage pressure around the pipe. The presence of the pipeline disturbs the flow-field, so that the flow pressures in front of the pipe are higher than those at the rear of it. This pressure drop further induces the seepage flow within the soil underneath the pipe. With the further increase of the current velocity, the critical state for onset of pipeline spanning is finally reached and a mixture of sand and water breaks through the space just at the downstream of the pipe ${ }^{[5]}$. In those small-scale flume experiments, it is very difficult to measure the pore pressure to obtain the distribution of the hydraulic gradients in the soil adjacent to the embedded pipe.

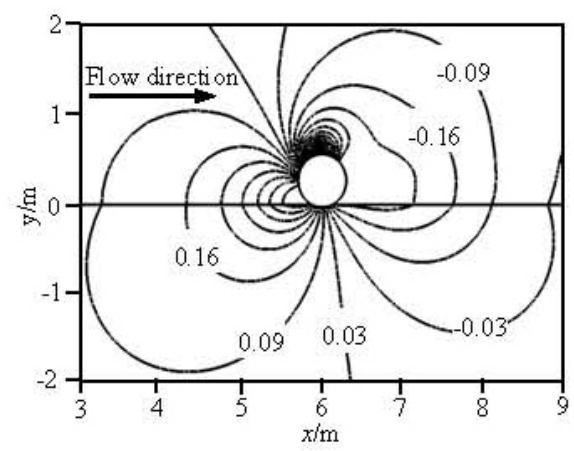

Fig.9 Contour of flow-pressure and seepage-pressure around the pipe (Unit: $\mathrm{kPa}) \quad\left(D=0.6 \mathrm{~m}, e_{0} / D=0.05\right.$, $U=1.0 \mathrm{~m} / \mathrm{s}$ )

Typical characteristics of the steady-current induced seepage-flow underneath the partially embedded pipe are shown in Fig.10, including the contour of hydraulic gradients, the seepage streamlines and flow vectors, which are given in Fig.10(a), 10(b) and 10(c), respectively. The maximum hydraulic gradients occur at the two corners upstream and downstream of the pipe (see Fig.10(a)). As the seepage forces at the upstream zone are in the direction downwards (see Fig.10(b) and 10(c)), the resistance to scouring would be increased. Nevertheless, the seepage forces at the downstream zone (see Fig.10(a)) are in the direction upwards, which may lead to soil seepage failure. In the proximity to the embedded pipe, the seepage streamlines are distributed along the pipe circumference (see Fig.10 (b)). The maximum seepage gradient at the downstream side of the pipe is in the direction upwards tangential to the pipe surface, as in good agreement with the location and direction of the breakout of the sand particles observed in the experiments (see Fig.3(b)). That is, the soil seepage failure as "piping" or "boiling" occurs closely adjacent to the downward intersection of the pipe and the soil surface (the exit of the seepage-flow).

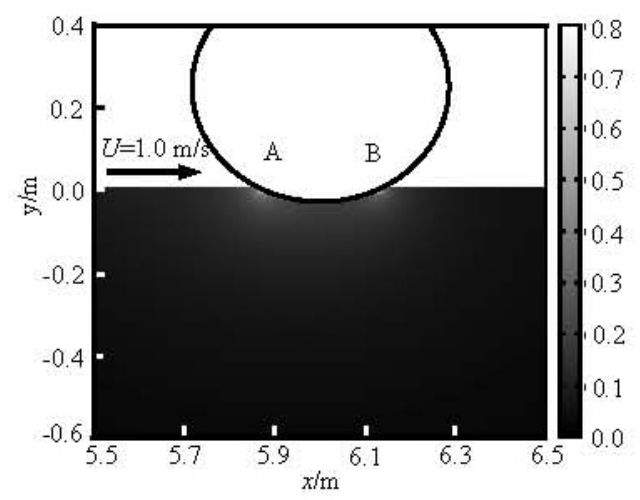

(a) Contour of hydraulic gradient

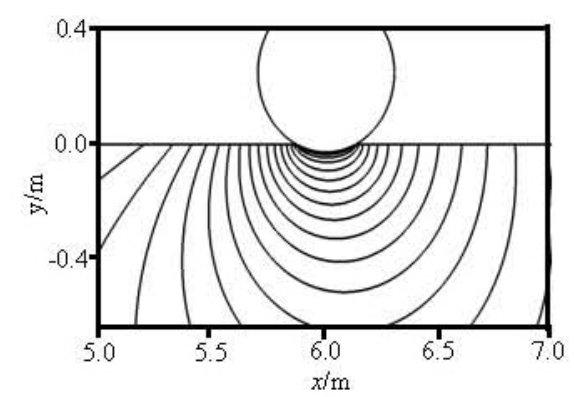

(b) Seepage-flow streamlines

Fig.10 Steady-current induced seepage-flow underneath the pipe: ( $U=1.0 \mathrm{~m} / \mathrm{s}, D=0.6 \mathrm{~m}, e_{0} / D=0.05$, the pipe is located at $x=6 \mathrm{~m}$ )

\subsubsection{Verification with experimental results}

When the hydraulic gradient at the seepage exit (see, point-B in Fig.10(a)) reaches the critical value for soil seepage failure, the process of pipeline spanning is initiated and the corresponding current velocity is regarded as the critical velocity (named as $U_{c r}$ ) for the onset of pipeline spanning. In the analyses by Sumer et al. ${ }^{[8]}$, the dimensionless critical flow velocity for pipeline spanning was expressed as

$$
V_{c r}=\frac{U_{c r}{ }^{2}}{(1-n)(s-1) g D}
$$

The numerical results are compared with the experimental data to verify the proposed numerical 
model. Figure 11 gives the comparisons of the present numerical results for soil piping failure, i.e., $i_{e x i t}=i_{c}$ (see Eq.(14)), with the experimental results. As shown in Fig.11, the dimensionless critical flow velocity $\left(V_{c r}\right)$ for the pipeline spanning increases with increasing pipe embedment $\left(e_{0} / D\right)$. The numerical results of the dimensionless critical flow velocity agree well with the experimental data.

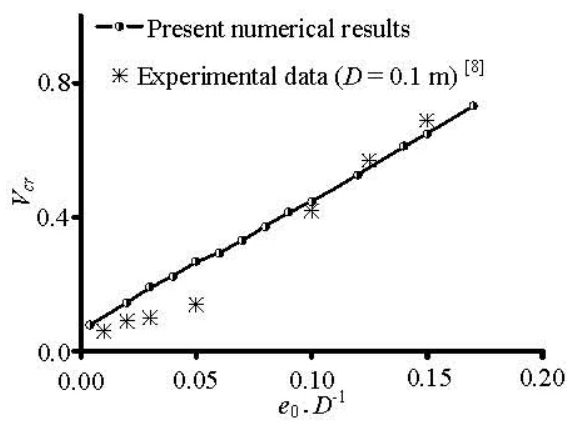

Fig.11 Comparisons between the present numerical results for soil piping failure and the experimental results ( $n=0.53, \phi=43^{\circ}, d_{50}=1.8 \times 10^{-4} \mathrm{~m}$, the water depth $(d=0.3 \mathrm{~m}))$

\section{Flow-pipe-seepage coupling analyses}

4.1 Effects of flow velocity, initial embedment on the pressure drop

As shown in Fig.9, there exists a pressure difference between the upstream and downstream of the pipeline, which leads to the seepage flow in the soil. The seepage-field may be influenced by various factors, such as the inflow velocity and initial embedment. Thus, it is meaningful to make a parametric study of the effects of the current velocity and the initial embedment on the pressure drops.

Figure 12(a) shows the pressure drops at the water-soil interface $\left(P_{s}\right)$ for various current velocities $(U)$, i.e. $U=0.2 \mathrm{~m} / \mathrm{s}, 0.5 \mathrm{~m} / \mathrm{s}$, and $1.0 \mathrm{~m} / \mathrm{s}$. It is indicated that, as the current velocity increases, the pressure drops increase dramatically, provided that the remaining parameters are kept unchanged. The pressure drops at the water-soil interface may also be affected by the initial embedment-to-diameter ratio $\left(e_{0} / D\right)$. Note that only the partially embedded pipe with a small embedment is considered in this study, e.g. $e_{0} / D=0.02,0.05,0.1$, and 0.2 (see Fig.12(b)). In the examined $e_{0} / D$ range $\left(0.02<e_{0} / D<0.2\right)$, the pressure drops decrease slightly with the increase of the embedment-to-diameter ratio.

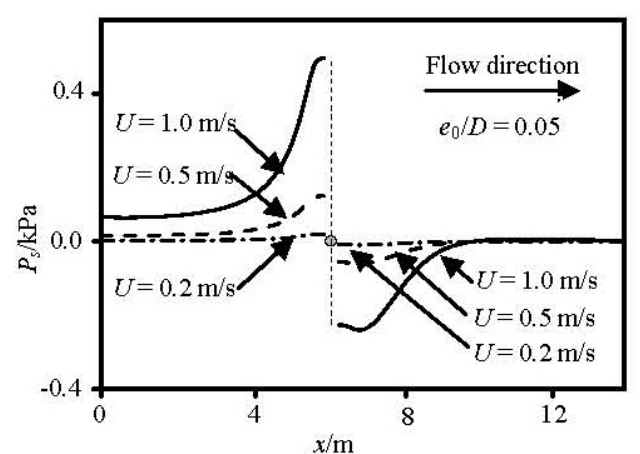

(a) For various current velocities

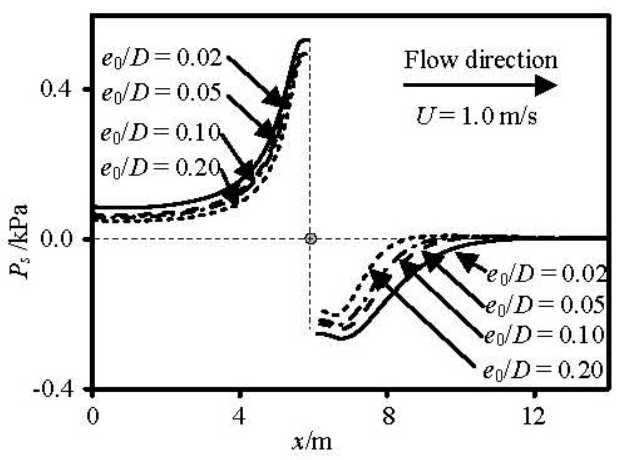

(b) For various current initial embedments

Fig.12 Pressure distributions at the water-soil interface near the pipe ( $D=0.6 \mathrm{~m}$, the pipe is located at $x=6 \mathrm{~m}$ )

4.2 Critical flow velocities for the onset of pipeline spanning underneath the partially embedded pipes

The critical flow velocity for pipeline spanning underneath the partially embedded pipe is an important issue in the pipeline engineering practice. With the increase of the velocity of ocean currents, the pressure-drop around the pipe increases accordingly (see Fig.12(a)), and the critical state for onset of pipeline spanning may be reached due to the soil seepage failure (see Fig.10).

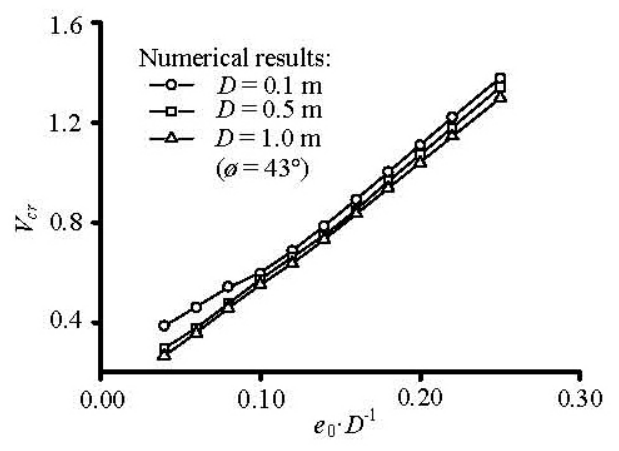

Fig.13 $V_{c r}$ versus $e_{0} / D$ for various pipe diameters 
Figure 13 gives the variation of $V_{c r}$ with $e_{0} / D$ for various pipe diameters, i.e., $D=0.1 \mathrm{~m}, 0.5 \mathrm{~m}$, and $1.0 \mathrm{~m}$. These " $V_{c r}-e_{0} / D$ ” curves for the case of small pipe diameters lie above those for the case of large pipe diameters (see Fig. 13), indicating that there exist scale effects for the " $V_{c r}-e_{0} / D$ " relations in the common pipeline diameter range $(0.05 \mathrm{~m}<D<1.0 \mathrm{~m})$.

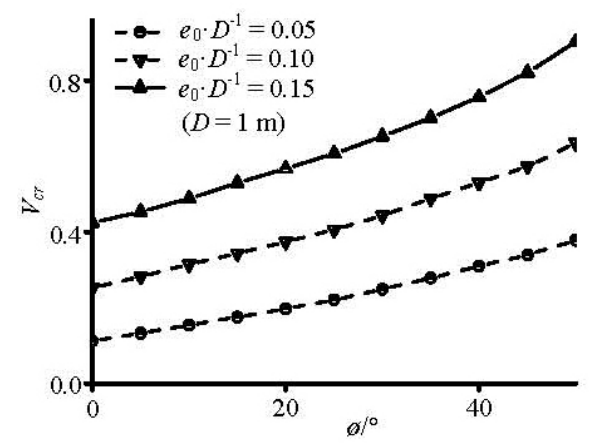

Fig.14 $V_{c r}$ versus $\phi$ for various embedment-to-diameter ratios

For the numerical model, an updated critical hydraulic gradient $\left(i_{c}\right)$ for the initiation of pipeline spanning (see Eq.(13)) is derived, in which two additional parameters are included, i.e., the internal friction angle of the soil $(\phi)$ and the initial pipe embedment-to-diameter ratio $\left(e_{0} / D\right)$. The effects of these two parameters on the critical flow velocity for pipeline spanning are investigated numerically. Figure 14 shows the numerical results of the relations between the dimensionless flow velocity $\left(V_{c r}\right)$ and the soil internal friction angle $(\phi)$ for various embedment-to-diameter ratios (e.g., $e_{0} / D=0.05$, 0.10 and 0.15 ). As shown in the figure, for fixed values of $e_{0} / D, V_{c r}$ increases with the increase of $\phi$, meanwhile, for a certain value of $\phi, V_{c r}$ increases with the increase of $e_{0} / D$ within the examined small pipe embedment range. Therefore, the influences of the soil internal friction angle and the pipe embedment on the critical flow velocity for pipeline spanning are significant.

It is noticed that, the slopes of the " $V_{c r}-e_{0} / D$ " curves (see Fig.13) are approximately constant for the fixed value of soil internal friction angle. Here, the following dimensionless parameter of the critical current velocity for pipeline spanning $\left(V^{*}\right)$ is introduced:
$V^{*}=\frac{U_{c r}^{2}}{(1-n)(s-1) g e_{0}}$

Then the numerical results in Fig.13 can be presented as the curves in Fig.15. For a given value of $\phi$, the dimensionless critical flow velocity $V^{*}$ for various pipe diameters decreases gradually and approaches to a constant (e.g., $V^{*}=5.4$ for $\phi=43^{\circ}, V^{*}=3.6$ for $\phi=20^{\circ}$, see Fig.15). As a conservative treatment for the convenience of engineering references, the critical flow velocity $\left(V^{*}\right)$ is mainly the function of soil internal friction angle $(\phi)$, i.e., $V^{*}=f(\phi)$. As indicated in Fig.16, the dimensionless critical flow velocity $V^{*}$ changes approximately linearly with soil internal friction angle $\phi$ in the examined range of embedment-to-diameter ratio $\left(0<e_{0} / D<0.25\right)$.

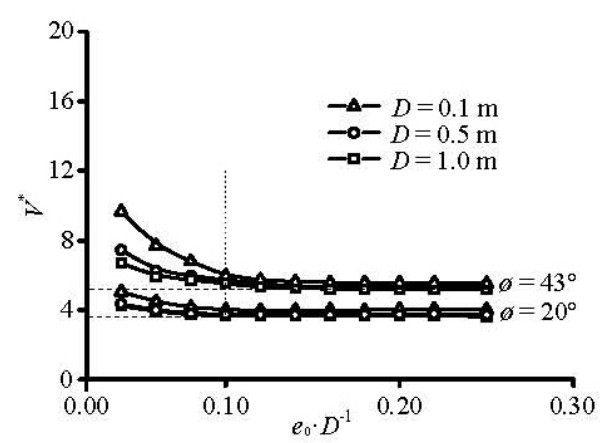

Fig.15 Variation of $V^{*}$ with $e_{0} / D$ for various pipe diameters and soil internal frictional angles

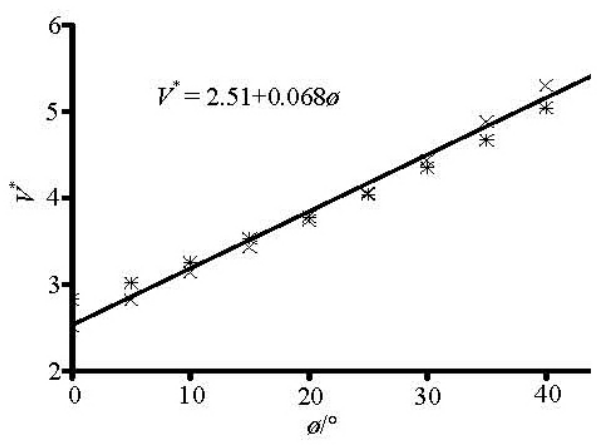

Fig.16 Relationship between $V^{*}$ and $\phi$ for partially embedded pipes

\section{Concluding remarks}

The pipeline spans may experience VIV, as is widely recognized as one of the main causes for 
fatigue damages of pipelines. The initiation of pipeline spanning involves the coupling between the flow over the pipeline and the seepage flow under the pipeline. The experimental observations show that the pressure drop induced soil seepage failure is the dominant cause for the onset of pipeline spanning.

A flow-pipe-seepage sequential coupling FEM model is proposed for implementing the coupling between water flow-field and soil seepage-field. A critical hydraulic gradient is derived for the oblique seepage failure of the sand underneath the pipe, in which two additional parameters are included, i.e., the internal friction angle of soil and the pipe embedment-to-diameter ratio.

Parametric study is performed to investigate the effects of flow velocity, pipe embedment on the pressure drop, and the effect of soil internal friction angle on the onset of pipeline spanning. Numerical results indicate that the influences of soil internal friction angle and pipe embedment on the critical flow velocity for pipeline spanning are significant. The critical dimensionless flow velocity changes approximately linearly with soil internal friction angle, in the examined range of embedment-to-diameter ratio $\left(0<e_{0} / D<0.25\right)$, which may provide a practical reference for evaluating the occurrence of pipe spanning under the action of ocean currents

\section{Acknowledgement}

Technical assistance from Dr. Yang Bing, Dr. Yan Shu-ming. and Senior Engineer Li Dong-hui in the flume experiments are greatly appreciated.

\section{References}

[1] HERBICH J. B. Offshore pipeline design elements[M]. New York: Marcel Dekker Inc., 1981.

[2] BLEVINS R. D. Flow-induced vibrations[M]. New York: Van Nostrand Reinhold Company, 1977.

[3] GAO F. P., YANG B. and WU Y. X. et al. Steady currents induced seabed scour around a vibrating pipeline[J]. Applied Ocean Research, 2006, 28(5): 291-298.

[4] ALLEN D. W., LAMMERT W. F. and HALE J. R. et al. Submarine pipeline on bottom stability: Recent AGA research[C]. Proceeding of 21st Annual Offshore Technology Conference. Houston, USA, OTC6055, 1989, 121-132.
[5] SUMER B. M., FREDSOE J. The mechanics of scour in the marine environment[M]. New Jersey: World Scientific Publishing Company, 2002.

[6] MAO Y. Seabed scour under pipelines[C]. Proceedings of 7th International Symposium on Offshore Mechanics and Arctic Engineering. Houston, USA, 1988, 33-38.

[7] CHIEW Y. M. Mechanics of local scour around submarine pipelines[J]. Journal of Hydraulic Engineering, 1990, 116(4): 515-529.

[8] SUMER B. M., TRUELSEN C. and SICHMANN T. et al. Onset of scour below pipelines and self-burial[J]. Coastal Engineering, 2001, 42(4): 313-335.

[9] BEARMAN P. W., ZDRVKOVICH M. M. Flow around a circular cylinder near a plan boundary[J]. Journal of Fluid Mechanics, 1978, 89(1): 33-47.

[10] BRORS B. Numerical modeling of flow and scour at pipelines[J]. Journal of Hydraulic Engineering, 1999, 125(5): 511-523.

[11] LIANG D., CHENG L. and LI F. Numerical modeling of flow and scour below a pipeline in currents Part II. Scour simulation[J]. Coastal Engineering, 2005, 52(1): 43-62.

[12] SHAN Syed Bilal Hussain, LU Xi-yun. Numerical simulation of an oscillating flow past a circular cylinder in the vicinity of a plane wall[J]. Journal of Hydrodynamics, 2008, 20(5): 547-552.

[13] LU Lin, LI Yu-cheng. and CHEN Bing. Mechanism of local scour around submarine pipelines based on numerical simulation of turbulence model [J]. Acta Oceanologica Sinica, 2006, 25(2): 142-152.

[14] LIANG D., CHENG L. A numerical model of onset of scour below offshore pipelines subject to steady currents[C]. Frontiers in Offshore Geotechnics: ISFOG 2005. London: Taylor and Francis Group, 2005, 637-643.

[15] YANG Bing, GAO Fu-ping and WU Ying-xiang. Numerical study of the occurrence of pipeline spanning under the influence of steady current[J]. Ship Building of China, 2005, 46(suppl.): 221-226(in Chinese).

[16] ZANG Z. P., CHENG L. and ZHAO M. et al. A numerical model for onset of scour below offshore pipelines[J]. Coastal Engineering, 2009, 56(4): 458-466.

[17] LUO Cheng-cai. Numerical investigation on mechanism of offshore pipeline spanning in steady ocean currents[D]. Master Thesis, Beijing: Institute of Mechanics, Chinese Academy of Sciences, 2008(in Chinese).

[18] FUJIMA S. Iso-P2 P1/P1/P1 domain-decomposition/ finite-element method for the Navier-Stokes equations[J]. Contemporary Mathematics, 1998, 218: 246-253. 